\title{
Correction to: Weight Reduction and Pioglitazone are Cost-Effective for the Treatment of Non-alcoholic Fatty Liver Disease in Thailand
}

\author{
Bunchai Chongmelaxme ${ }^{1} \cdot$ Pochamana Phisalprapa $^{2} \cdot$ Ratree Manthaisong $^{3,4} \cdot$ Piyameth Dilokthornsakul $^{1}$ (1) \\ Nathorn Chaiyakunapruk ${ }^{1,4,5,6}$
}

Published online: 13 December 2018

(c) Springer Nature Switzerland AG 2018

\section{Correction to: PharmacoEconomics https://doi.org/10.1007/s40273-018-0736-0}

The title of the article should read:

Weight Reduction is Cost-Effective for the Treatment of Non-alcoholic Fatty Liver Disease in Thailand.

The original article can be found online at https://doi.org/10.1007/ s40273-018-0736-0.

Piyameth Dilokthornsakul piyamethd@gmail.com

$\triangle$ Nathorn Chaiyakunapruk nathorn.chaiyakunapruk@monash.edu

1 Center of Pharmaceutical Outcomes Research, Departmentof Pharmacy Practice, Faculty of Pharmaceutical Sciences, Naresuan University, 65000 Phitsanulok, Thailand

2 Department of Medicine, Faculty of Medicine Siriraj Hospital, Mahidol University, Bangkok, Thailand

3 Clinical Pharmacy Research Unit, Department of Clinical Pharmacy, Faculty of Pharmacy, Mahasarakham University, Mahasarakham, Thailand

4 School of Pharmacy, Monash University Malaysia, Selangor, Malaysia

5 School of Pharmacy, University of Wisconsin, Wisconsin, MA, USA

6 Asian Centre for Evidence Synthesis in Population, Implementation and Clinical Outcomes (PICO),

Health and Well-Being Cluster, Global Asia in the 21st Century (GA21) Platform, Monash University Malaysia, Bandar Sunway, Selangor, Malaysia 